NASA Technical Memorandum 83611

\title{
Aerodynamic Effect of Combustor Inlet-Air Pressure on Fuel Jet Atomization
}

Robert D. Ingebo

Lewis Research Center

Cleveland, Ohio

Prepared for the

Twentieth Joint Propulsion Conference cosponsored by the AIAA, SAE, and ASME

Cincinnati, Ohio, June 11-13, 1984 
AERODYNAMIC EFFECT OF COMBUSTOR INLET-AIR PRESSURE ON FUEL JET ATOMIZATION

by Robert $D$. Ingebo

National Aeronautics and Space Administration

Lewis Research Center

Cleveland, Ohio 44135

\section{Abstract}

Mean drop diameters were measured with a recently developed scanning radiometer in a study of the atomization of liquid jets injected cross stream in high velocity and high pressure airflows. At constant inlet-air pressure, reciprocal mean drop diameter, $\mathrm{D}_{\mathrm{m}}^{-1}$, was correlated with airflow mass velocity, $\rho_{a} v_{a}$, to give the relationship $D_{\mathrm{m}}^{-1} \sim$

\& $\left(\rho_{a} V_{a}\right)^{1.2}$ for a $\rho_{a} V_{a}$ range of 10 to

O $177 \mathrm{~g} / \mathrm{cm}^{2}-\mathrm{sec}$ at $293 \mathrm{~K}$. Over a combustor

山 inlet-air pressure range of 1 to 21 atmospheres, the ratio of orifice to mean drop diameter, $D_{0} / D_{m}$, was correlated with the product of Weber and Reynolds number, WeRe, and with the molecular-scale momentum-transfer ratio of gravitational to inertial forces, $g l / \bar{c}^{2}$, as follows: $D_{0} / D_{m}=1.4(\text { WeRe })^{0.4}\left(\mathrm{~g} l / \bar{c}^{2}\right)^{0.15}$ for values of WeRe $>10^{6}$, where WeRe $=0 D^{2} v_{r}^{3}$, $\sigma \gamma, \rho_{a}$ and $V_{r}$ are airstream density and velocity, respectively, $\sigma$ and $\gamma$ are liquid surface tension and kinetic viscosity, respectively, $g$ is the acceleration due to gravity, $980 \mathrm{~cm} / \mathrm{sec}^{2}, 1$ is mean free molecular path, $6.11 \times 10^{-6} \mathrm{~cm}$ for air at atmospheric pressure, and $\bar{c}$ is root-mean-square molecular velocity, $4.85 \times 10^{4} \mathrm{~cm} / \mathrm{sec}$ for air at $273 \mathrm{~K}$.

\section{Nomenclature}

$\overline{\mathrm{C}}$ $b_{g, w}$ D diameter, $\mathrm{cm}$

D32 Sauter mean diameter, $\Sigma \mathrm{nD}^{3} / \Sigma \mathrm{nD}^{2}, \mathrm{~cm}$

$\mathrm{g}$ acceleration due to gravity, $980 \mathrm{~cm} / \mathrm{sec}^{2}$

1 mean free molecular path, cm

M molecular weight

$\mathrm{Nu} \quad$ Nusselt number for heat transfer, hD/k

$n$ number of molecules per unit volume

$P \quad$ static pressure, atm

$R$ universal gas constant, $8.31 \times 10^{7}$ $\operatorname{ergs/(K)}$ (mole)

Re Reynolds number based on orifice diameter, $D_{0} V_{r} / r_{1}$

Sc Schmidt number based on mass diffusivity, $\mu / b_{g} w$

$v \quad$ velocity, $\mathrm{cm} / \mathrm{sec}$

We Weber number based on orifice diameter, $\mathrm{D}_{0} \rho_{\mathrm{a}} \mathrm{V}_{\mathrm{r}}^{\mathrm{s} / \sigma}$

$\gamma \quad$ kinematic viscosity, $\mathrm{cm}^{2} / \mathrm{sec}$

$\sigma$ surface tension, dynes/cm

$\rho$ density, $\mathrm{g} / \mathrm{cm}^{3}$

$\mu \quad$ absolute viscosity, $\mathrm{g} / \mathrm{cm}-\mathrm{sec}$

\section{Subscripts:}

$\begin{array}{ll}\text { a } & \text { airstream } \\ g & \text { gas molecule } \\ 1 & \text { liquid } \\ m & \text { mean } \\ 0 & \text { orifice } \\ r & \text { relative } \\ v & \text { vapor }\end{array}$

\section{Introduction}

An experimental investigation was conducted to determine the effect of combustor inlet airflow static pressure on mean drop diameters obtained by atomization of water jets injected cross stream from simple orifices into axial flow airstreams. An improved scanning radiometer was developed at NASA Lewis Research Center and used to obtain mean drop diameter data for sprays. Such data are needed to supplement previous theoretical and experimental studies of liquid atomization in order to extend our knowledge to aerodynamic breakup of fuels in both high pressure and high velocity airflows.

Previous studies have shown that the force or mass velocity of an airstream is a very important factor in determining the fineness of atomization of fuel in a combustor primaryzone. As a result, the effect of airstream mass velocity on fuel atomization is receiving considerable attention in advanced combustor research investigations. 1 Also, earlier studies have shown that high combustion efficiencies can be attained and exhaust emissions reduced by controlling the aerodynamic force of the airstream, in the breakup of liquid fuel jets, instead of relying on hydrodynamic pressure drop of the fuel to do the work as is the case in the use of pressure atomizing fuel nozzles. 2 The high combustion efficiency and reduction in pollutants was attributed to improved fuel atomization. This conclusion was substantiated in a later study ${ }^{3}$, in which it was found that nitrogen oxide emissions in the exhaust gases of swirl can combustor modules varied directly with the square of the mean drop diameter of the fuel spray.

The present trend of advanced combustor research toward higher primary-zone inlet air pressures and temperatures has stimulated the need to know the effect of airstream pressure on fuel atomization and combustion. Although there are very little data available that show this effect, expressions have been derived which relate Weber and Reynolds numbers to the mean drop diameter of fuel sprays and predict the effect of airstream pressure on mean drop size. 
Different expressions have been derived depending on whether atomization occurs in the capillary-wave or acceleration-wave regimes. In Ref. 4 it was found, when transition from capillary to acceleration or aerodynamic wave breakup occurs the effect of the product of the Weber and Reynolds number on mean drop size increases considerably. As a result, a marked change in the effect of airstream pressure on mean drop size is also predicted. Such a correlation is quite useful in the design of fuel injectors for combustor applications since fuel nozzles can be calibrated with water and mean drop diameters can then be calculated for the desired fuel, such as Jet-A, with the aid of such correlations.

In the present investigation, relationships involving the product of Weber and Reynolds number investigated for the condition WeRe $>10^{6}$. The acceleration or aerodynamic wave breakup regime was chosen for investigation since high velocity airstreams are required in simulating fuel atomization in turbojet combustors at idle, take-off and cruise operating conditions. Thus, water jets were injected from an airfoil type of spray bar cross stream or normal to the airflow and mean drop diameters of the sprays were measured with an improved scanning radiometer recently developed at NASA Lewis Research Center. Combustor in let-air static pressure was varied from 1 to 21 atmospheres over a range of airflow rates per unit area of 10 to $177 \mathrm{~g} /\left(\mathrm{cm}^{2}\right)(\mathrm{sec})$, at $293 \mathrm{~K}$. Spray bar orifice diameters were varied from 0.033 to $0.132 \mathrm{~cm}$ and liquid flowrates from 27 to 68 liters per hr. Mean drop diameter data were then correlated with the product of Weber and Reynolds number and the pressure sensitive molecular scale dimensionless group $\mathrm{gl} / \overline{\mathrm{c}}^{2}$. The resulting empirical relationships for liquid-jet breakup were compared with those obtained from a previous experimental study of cross stream injection of radial jets in high velocity airflow. 4

\section{Apparatus and Procedure}

The test section is shown in Fig. 1 with two 5.1-cm-diam windows passing laser light beam through the spray of droplets produced in the high velocity and high pressure airflow. The closed-duct high pressure test facility in which the test section was mounted is shown in Fig. 2. Airflow was drawn from the laboratory supply system, at ambient temperature (293 K) and exhausted into the altitude exhaust system to obtain drop size data at low airstream pressure and into the atmosphere for high pressure airflow test conditions. The airflow control valve was opened until the desired airlflow rate per unit area was obtained. The bellmouth test section shown in Fig. 3 has a total length of $0.152 \mathrm{~m}$, an inside diameter of $0.076 \mathrm{~m}$ and is mounted inside of a duct that is $2.1 \mathrm{~m}$ in length with an inside diameter of $0.152 \mathrm{~m}$.

Multiple jets of water were injected at the duct center line and directed cross stream with the fuel spray bar shown in Fig. 3. Water flowrate was controlled, by gradualiy opening and requlating the valve, over a range of 27 to 68 liters per hr. One of the fuel spray bars is shown in detail in Fig. 4. Three different spray bars were investigated to obtain drop size data over an orifice diameter range of 0.033 to $0.130 \mathrm{~cm}$. The first spray bar had twelve $0.033-\mathrm{cm}-\mathrm{diam}$ orifices, the second had four $0.102-\mathrm{cm}-\mathrm{diam}$ orifices and the final configuration had three $0.130-\mathrm{cm}-d i a m$ orifices, respectively. Thus, at a liquid flowrate of 22.7 liters per $\mathrm{hr}$. 1iquid/jet velocities were 614,194 , and $158 \mathrm{~cm} / \mathrm{sec}$, respectively, for the three spray bars.

After water and airflow rates were set, mean drop diameter data were obtained with the scanning radiometer mounted $25.4 \mathrm{~cm}$ downstream of the fuel tube supporting the spray bar. The scanning radiometer optical system shown in $\mathrm{Fig}$. 5 consisted of a 1-milliwatt helium-neon laser, a 0.003-cm-diam aperture, a 7.5-cm-diam collimating lens, a 10-cm-diam converging lens, a 5-cm-diam collecting lens, a scanning disk with a 0.5 by $2.5 \mathrm{~cm} \mathrm{slot,} \mathrm{a} \mathrm{timing} \mathrm{light,} \mathrm{and} \mathrm{a}$ photo-multiplier detector. A more complete discription of the improved scanning radiometer, the mean drop diameter range of 10 to $500 \mu \mathrm{m}$, and the method of determining mean particle size are discussed in Refs. 5 and 6.

\section{Experimental Results}

To obtain a better understanding of liquid jet atomization theory and thereby advance fuel injection technology for jet engine applications, the aerodynamic-wave breakup of liquid jets in high pressure and high velocity airflow was investigated in a simulated gas turbine combustor primary-zone. Mean drop diameter data were obtained for water jets atomized under simulated high pressure combustor inlet airflow conditions. The atomization of a liquid jet in an axial-flow airstream is depicted in Fig. 6 as a process of forming ligaments from the crests of waves formed on the surface of a liquid jet. The ligaments are then atomized into drops. Short wave-length disturbances near the tip of the injector produced relatively small droplets whereas long wavelength disturbances farther out in the airstream produced relatively large drops.

Airstream Mass Velocity Effect on Mean Drop Size

Mean drop diameter data were determined for the breakup of water jets injected cross stream in axial airflows. As a measure of fineness of atomization or spray specific surface area, the reciprocal mean drop diameter, $\mathrm{Dm}^{-1}$, was determined with the scanning radiometer and plotted against mass velocity, $\rho_{a} V_{a}$, as shown in Fig. 7. The reciprocal of the mean drop diameter, $D_{m}^{-1}$, was used since it is useful in characterizing a spray in terms of the surface area per unit volume of the spray and $c$ an be defined as:

$$
D_{m}^{-1} \sim D_{32}^{-1}=\frac{\Sigma n D^{2}}{\Sigma n D^{3}}=D_{23}
$$

where $D_{23}$ is a single drop having the same ratio of surface area to volume as that of the entire spray. 
Figure 7 shows the effect of airstream momentum, or mass velocity, on mean drop diameter, $D_{m}^{-1}$, at seven different inlet-air pressures over a range of 1 to 21 atmospheres. The slope of each of the seven plots indicates that the expression $D_{m}^{-1} \sim\left(\rho_{a} V_{a}\right)^{1.2}$, which was obtained in Ref. 4, is valid over the entire inlet-air pressure range used in this study.

From the plot in Fig. 7 it is evident that, at a high combustor inlet-air pressure of 21 atmospheres, a very high airflow mass velocity of $200 \mathrm{~g} /\left(\mathrm{cm}^{2}\right)(\mathrm{sec})$ is required to produce a spray having a value of $D_{m}^{-1}=300 \mathrm{~cm}^{-1}$. On the other hand, a mass velocity of only 30 $\mathrm{g} /\left(\mathrm{cm}^{2}\right)(\mathrm{sec})$ was required to produce the same mean drop size at an inlet-air pressure of only 2 atmospheres.

\section{WeRe Effect on Mean Drop Size}

In a previous study described in Ref. 7 , it was found that the mean drop size of sprays produced by cross stream injection of a number of different liquids into airstreams could be correlated with the product of the Weber number and the Reynolds number, WeRe, as follows:

$$
\frac{D_{0}}{D_{32}}=0.20(\text { WeRe })^{0.25} \text { for WeRe }<10^{6}
$$

for the case of capillary-wave breakup of liquid jets. However more recently it was shown in Ref. 4 that, at high values of airstream mass velocity, aerodynamic-wave breakup occurs and the expression becomes:

$$
\frac{D_{0}}{D_{m}}=0.027(\text { WeRe })^{0.4} \text { for WeRe }>10^{6}
$$

and the transition from capillary-wave to aerodynamic-wave breakup occurs at WeRe $=10^{6}$ as shown in Fig. 8 which is taken from Ref. 4 .

Aerodynamic-wave breakup is the regime of primary concern in this study, that is, WeRe > $10^{6}$ as given in Eq. (3). This is demonstrated in Fig. 9 where experimental values of $D_{0} / D_{m}$ are plotted against calculated values of WeRe. The slope of each plot shows good agreement with the exponent 0.4 as given in Eq. (3) for aerodynamic-wave breakup of liquid jets.

\section{Airstream Pressure Effect on Mean Drop Size}

In a previous study described in Ref. 8 , it was found that heat transfer coefficients for vaporizing drops and Nusselt number, Nu could be correlated with the product of the Reynolds and Schmidt numbers, ReSc. Also it was found that a new pressure sensitive dimensionless group, $\mathrm{gl} / \overline{\mathrm{c}}^{2}$, was needed in the correlation to make it valid over an airstream static pressure range of 0.59 to 1.97 atmospheres. Thus, the following semiempirical expression was derived:

$$
\mathrm{Nu}=2+2.6 \times 10^{6}\left(\operatorname{ReSc} \mathrm{gl} / \overline{\mathrm{c}}^{-2}\right)^{0.6}\left(\mathrm{k}_{\mathrm{g}} / \mathrm{k}_{\mathrm{v}}\right)^{0.5}
$$

where $\mathrm{Nu}=\mathrm{hD} / \mathrm{k}, \mathrm{Re}=\mathrm{DV} / \gamma_{1}$ and $\mathrm{Sc}=$ $\mu / \mathrm{b}, \mathrm{w}$. In the formation of a spray of drops, it cowild also be assumed that the reciprocal mean drop diameter might be a function of the molecular scale momentum-transfer ratio of gravitational to inertial forces, $\mathrm{gl} / \overline{\mathrm{c}}^{2}$, as follows:

$$
\frac{D_{0}}{D_{m}}=f\left(\text { WeRe, } g / \bar{c}^{2}\right)
$$

To test the validity of this assumption, $D_{0} / D_{m}$ (WeRe $)^{-0.4}$ is plotted against the dimensionless group $\mathrm{gl} / \mathrm{C}^{-2}$ as shown in Fig. 10 . From the slope of this plot, it is evident that $\mathrm{D}_{0} / \mathrm{D}_{\mathrm{m}} \sim \mathrm{gl} / \mathrm{C}^{2}$. Thus by plotting $\mathrm{D}_{0} / \mathrm{D}_{\mathrm{m}}$ against (WeRe) ${ }^{0.4}\left(\mathrm{~g} / / \overline{\mathrm{c}}^{-2}\right)^{0.15}$ as shown in Fig. 11, the following expression is obtained:

$$
\frac{D_{0}}{D_{m}}=1.4(\text { WeRe })^{0.4}\left(\mathrm{~g} l / \bar{c}^{-2}\right)^{0.15}
$$

for aerodynamic breakup of liquid jets injected cross stream in high-pressure high-velocity airflow. This expression shows that the effect of combustor inlet-air pressure, $\mathrm{P}_{\mathrm{a}}$, on reciprocal mean drop diameter, $D_{m}$, can be written as, $D_{m}^{-1} \sim p_{a}^{0.25}$, since $\left(g l / \bar{c}^{2}\right)^{0.15}$ $\sim \mathrm{P}_{\mathrm{a}}-0.15$ and (WeRe) $0.4 \sim \mathrm{PQ}^{4}$. Equation (6) also indicates that $D_{\mathrm{m}}^{-1} \sim \rho \mathrm{O} .4$ whereas acceleration-wave breakup theory predicts $D_{\mathrm{m}}^{-1}$ $\sim \rho .66$. Thus, the effect of combustor inleta ir temperature on mean drop size needs to be investigated at high airstream temperatures in order to actually determine the effect of combustor inlet-air density on the mean drop diameter of fuel sprays. Such a study would entail the difficulty of determining the drop size of rapidly evaporating sprays.

\section{Summary of Results}

Empirical correlations of reciprocal mean drop diameter with airstream mass velocity were derived for aerodynamic-wave breakup of liquid jets injected cross stream in airflow with combustor inlet-air pressures ranging from 1 to 21 atmospheres. A newly developed scanning radiometer was used to obtain atomization data over an airstream mass velocity range of 10 to $177 \mathrm{~g} /\left(\mathrm{cm}^{2}\right)(\mathrm{sec})$ at $293 \mathrm{~K}$. The results of this investigation are as follows:

1. At constant combustor inlet-air pressure, the reciprocal mean drop diameter, $\mathrm{D}_{\mathrm{m}}^{-1}$, was correlated with airflow mass velocity, $\rho_{a} V_{a}$, to give the relationship:

$$
D_{m}^{-1} \sim\left(\rho_{a} V_{a}\right)^{1.2}
$$

2. With values of WeRe $>10^{6}$ and over a combustor inlet-air pressure range of 1 to 21 atmospheres, the ratio of orifice to mean drop 
diameter, $D_{0} / D_{m}$, was correlated with the product of Weber and Reynolds number, WeRe, and with the pressure sensitive dimensionless group, $\mathrm{gl} / \overline{\mathrm{c}}^{2}$, as follows:

$$
\frac{D_{0}}{D_{m}}=1.4(\text { WeRe })^{0.4}\left(\mathrm{gl} / \overline{\mathrm{C}}^{-2}\right)^{0.15}
$$

where $\mathrm{gl} / \mathrm{c}^{-2}=2.55 \times 10^{-12}$ for airstreams at atmospheric pressure.

\section{Appendix}

Calculation of Molecular-Scale Momentum-Transfer Group, $\mathrm{g} l / \mathrm{c}^{2}$

The mean free molecular path 1 may be expressed as:

$$
1=1 / \sqrt{2} \mathrm{nDg}^{2}=6.11 \times 10^{-6} \mathrm{~cm}
$$

since the number of molecules per unit volume $n$ is $2.7 \times 10^{19}$ at a temperature of $0^{\circ} \mathrm{C}$ and $\mathrm{a}$ pressure of one atmosphere and the diameter of an air molecule, $D_{\mathrm{g}}$, is $3.7 \times 10^{-8} \mathrm{~cm}$.

The root-mean-squate molecular velocity $\bar{c}$ may be expressed as $\bar{c}=(3 R T / M)^{0.5}$ which yields:

$$
\bar{c}^{-2}=\frac{(3)\left(8.31 \times 10^{7}\right)(273)}{(29)}=2.35 \times 10^{9}(\mathrm{~cm} / \mathrm{sec})^{2}
$$

Since $g$ is $980 \mathrm{~cm}$ per sec per sec:

$$
\mathrm{g} 1 / \overline{\mathrm{c}}^{2}=\frac{(980)\left(6.11 \times 10^{-6}\right)}{\left(2.35 \times 10^{9}\right)}=2.55 \times 10^{-12}
$$

\section{References}

1. Ingebo, R. D., "Aerodynamic-Wave Break-Up of Liquid Sheets in Swirling Airflows and Combustor Modules", NASA TM-83353, 1983.

2. Ingebo, R. D., Doskocil, A. J. and Norgren, C. T., "High Pressure Performance of Combustor Segments Utilizing Pressure-

Atomizing Fuel Nozzles and Airswirlers for Primary-Zone Mixing," NASA TN D-6491, 1971.

3. Ingebo, R. D., "Atomizing Characteristics of Swirl Can Combustor Modules with Swirl Blast Fuel Injectors in Terms of N0X Emission Rate," NASA TM-79297, 1980.

4. Ingebo, R. D., "Capillary and Acceleration Wave Breakup of Liquid Jets in Axial-Flow Airstreams," NASA TP-1791, 1981.

5. Buchele, D. R., "Scanning Radiometer for Measurement of Forward-Scattered Light to Determine Mean Diameter of Spray Particles," NASA TM X-3454, 1976.

6. Buchele, D. R., "Particle Sizing by Measurement of Forward-Scattered Light at Two Angles," NASA TP-2156, 1983.

7. Ingebo, R. D., Foster, H. H., "Drop-Size Distribution for Cross-Current Breakup of Liquid Jets in Airstreams," NACA TN-4087, 1957 .

8. Ingebo, R. D., "Study of Pressure Effects on Vaporization Rate of Drops in Gas Streams," NACA TN-2850, 1953. 


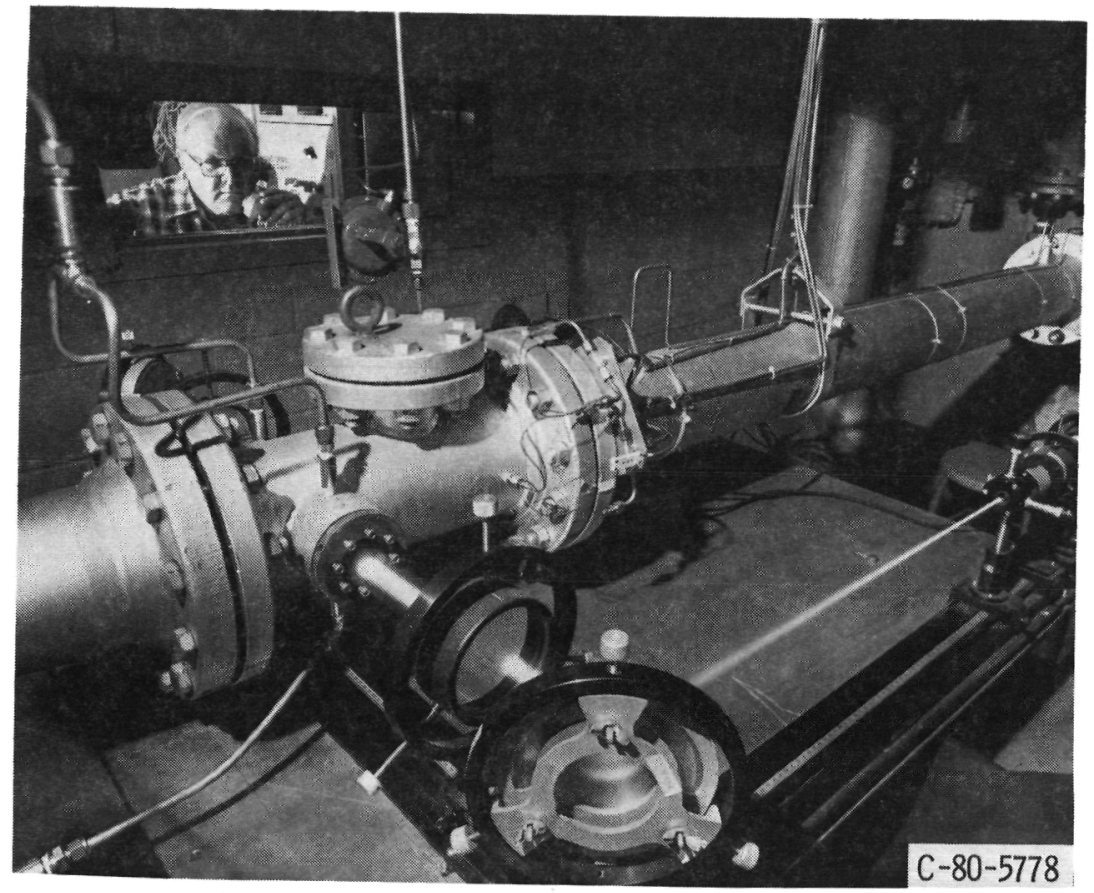

Figure 1. - Apparatus and auxillary equipment. 


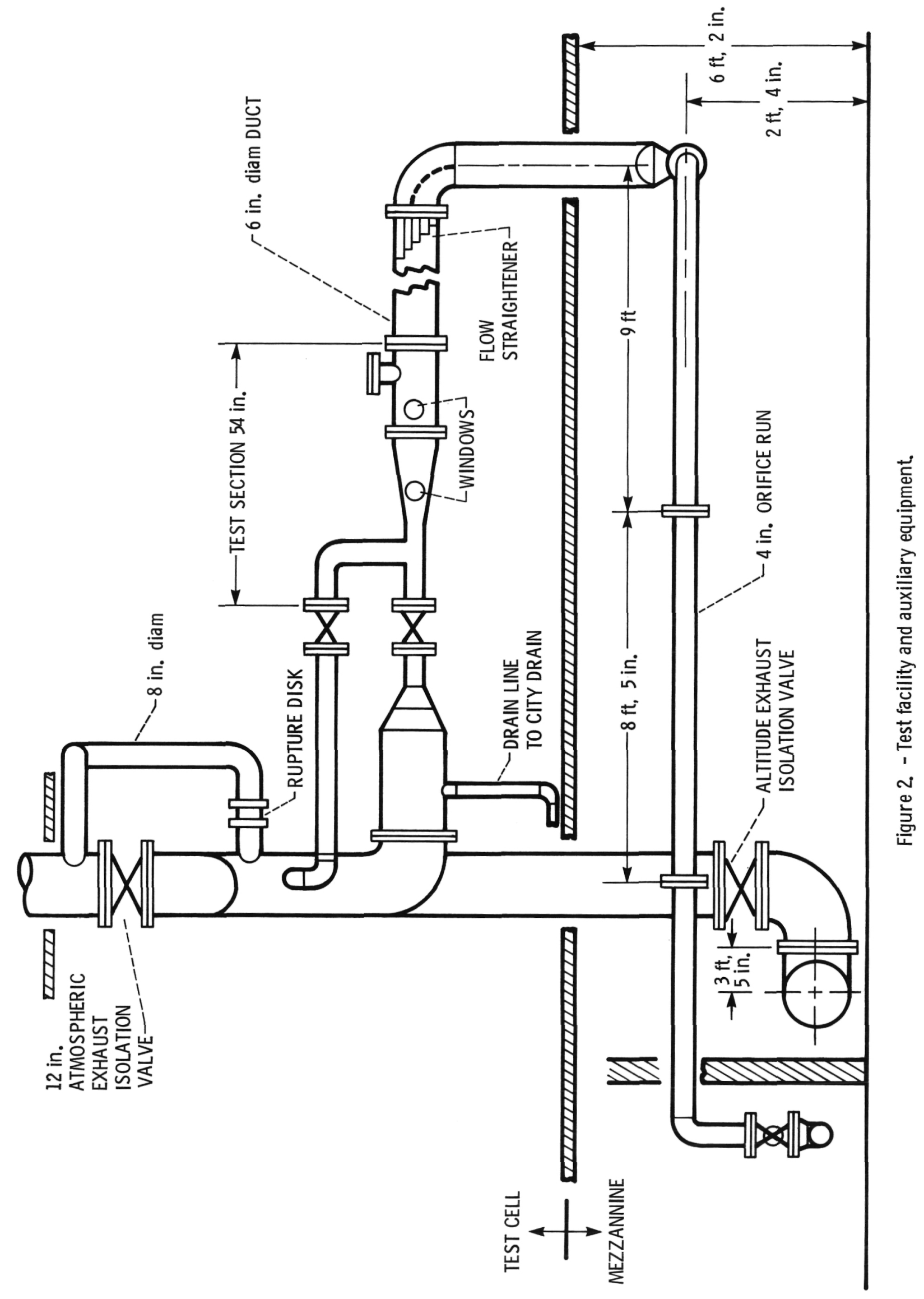




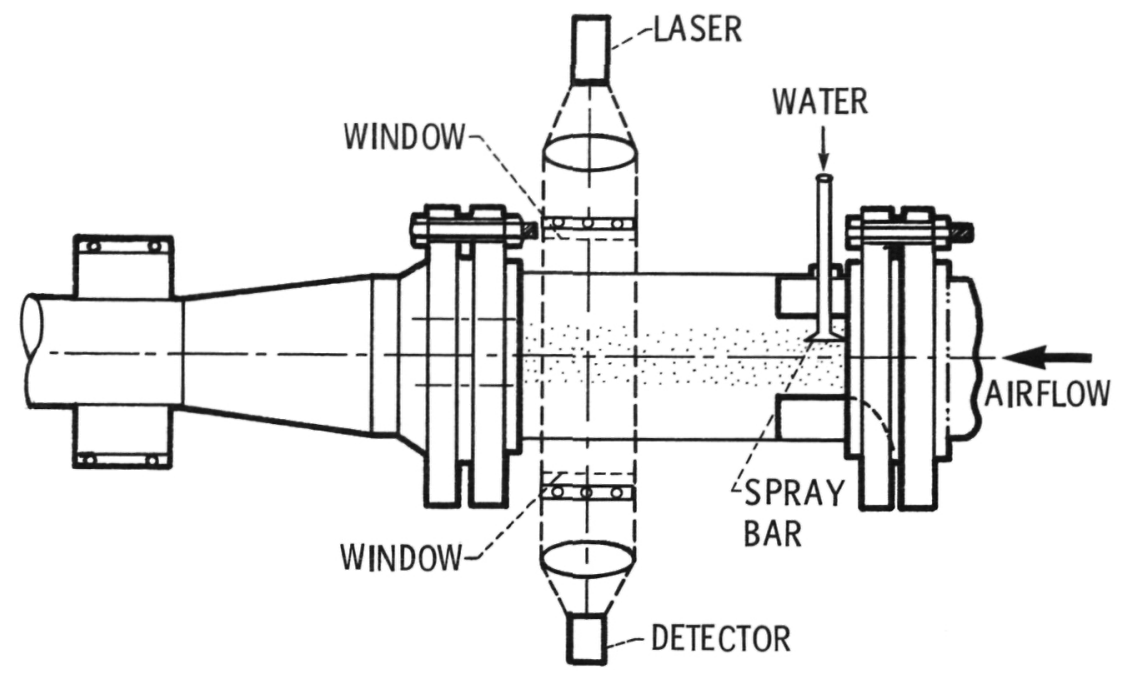

Figure 3. - High pressure test section.

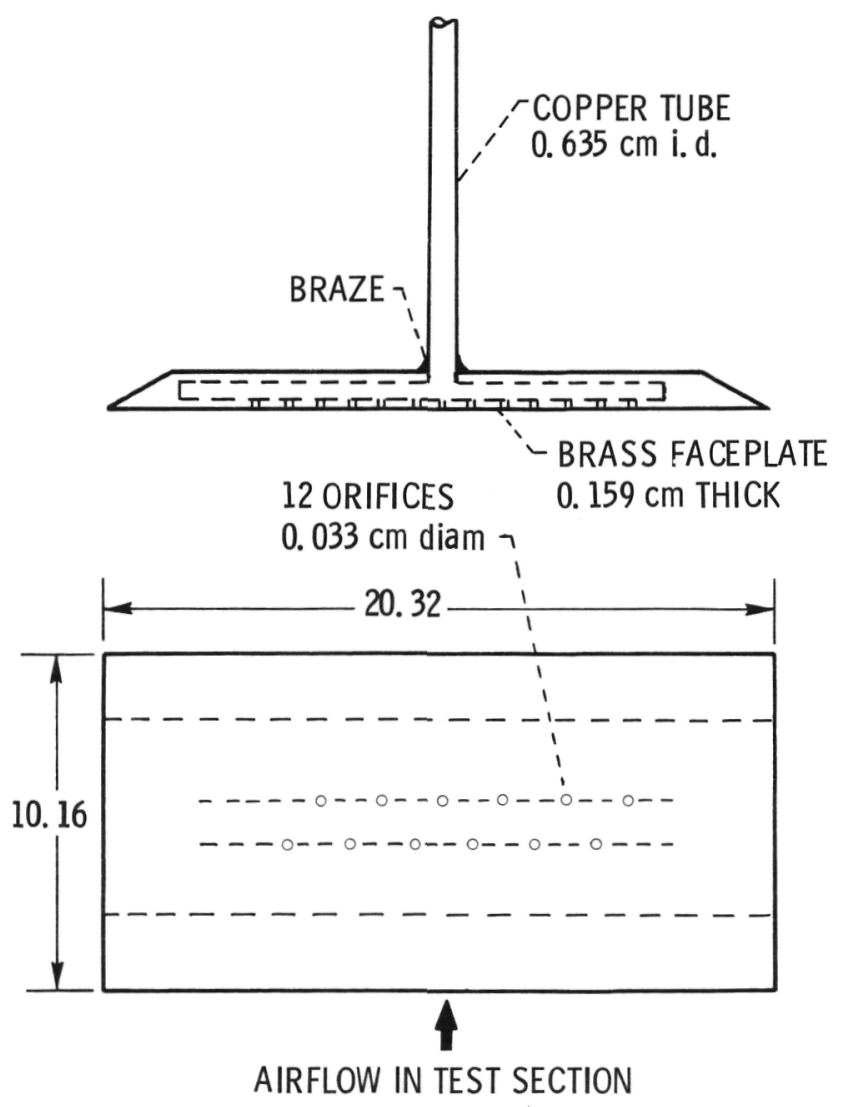

Figure 4. - Schematic diagram of multiple-orifice spray bar. (Dimensions are in centimeters.) 


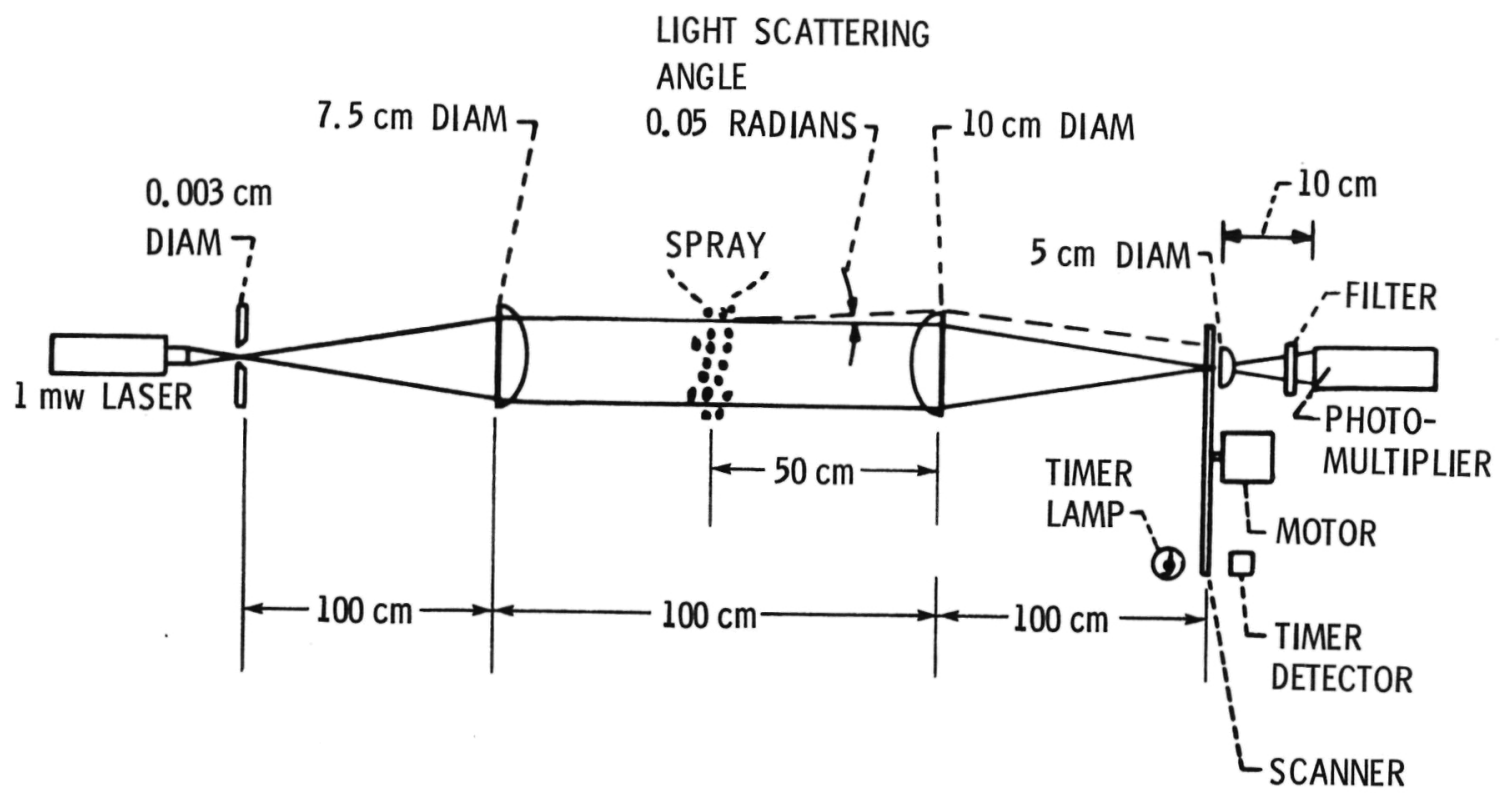

Figure 5. - Scanning radiometer optical path. 


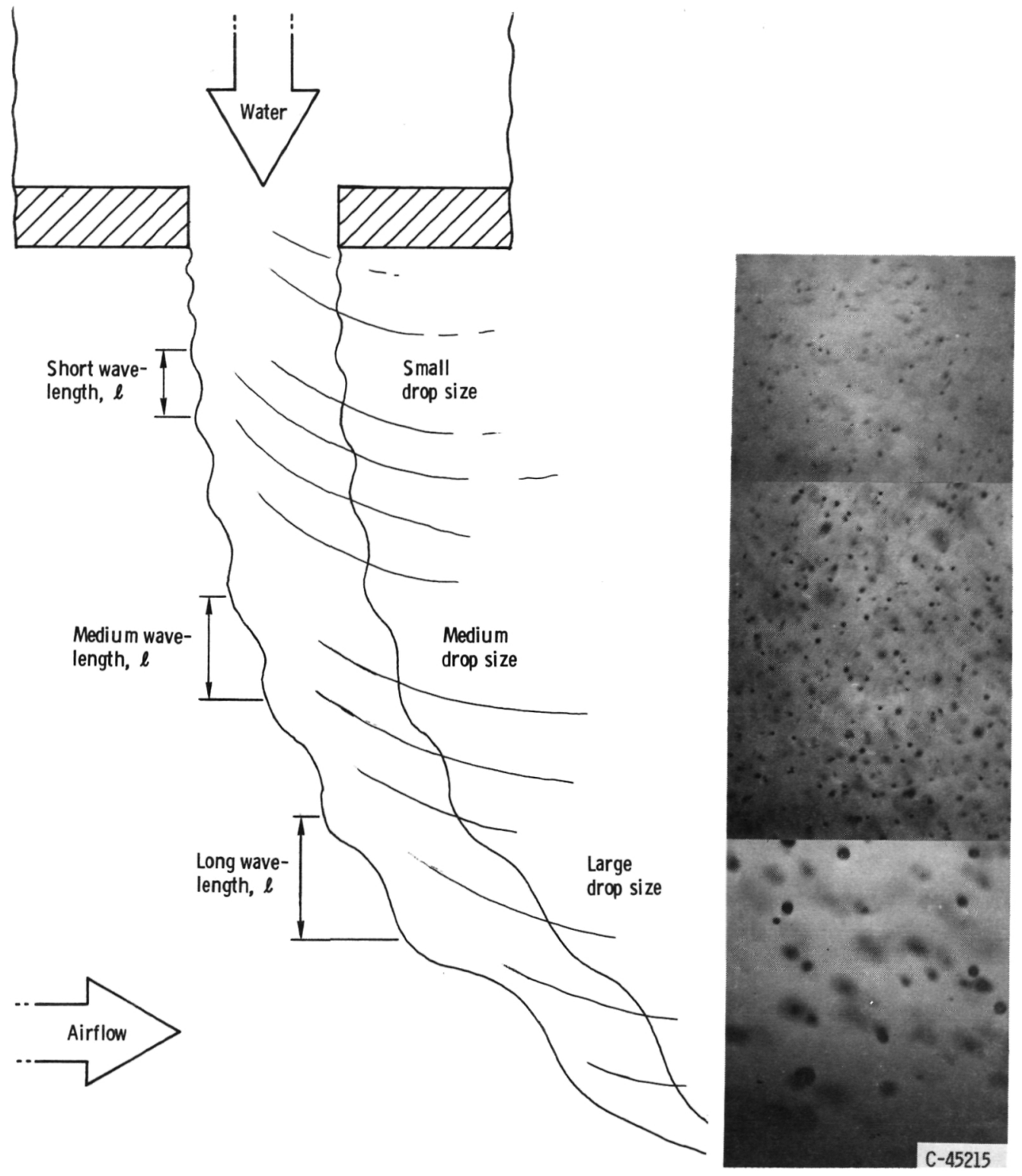

Figure 6. - Schematic of a liquid jet breaking up into ligaments and drops. 

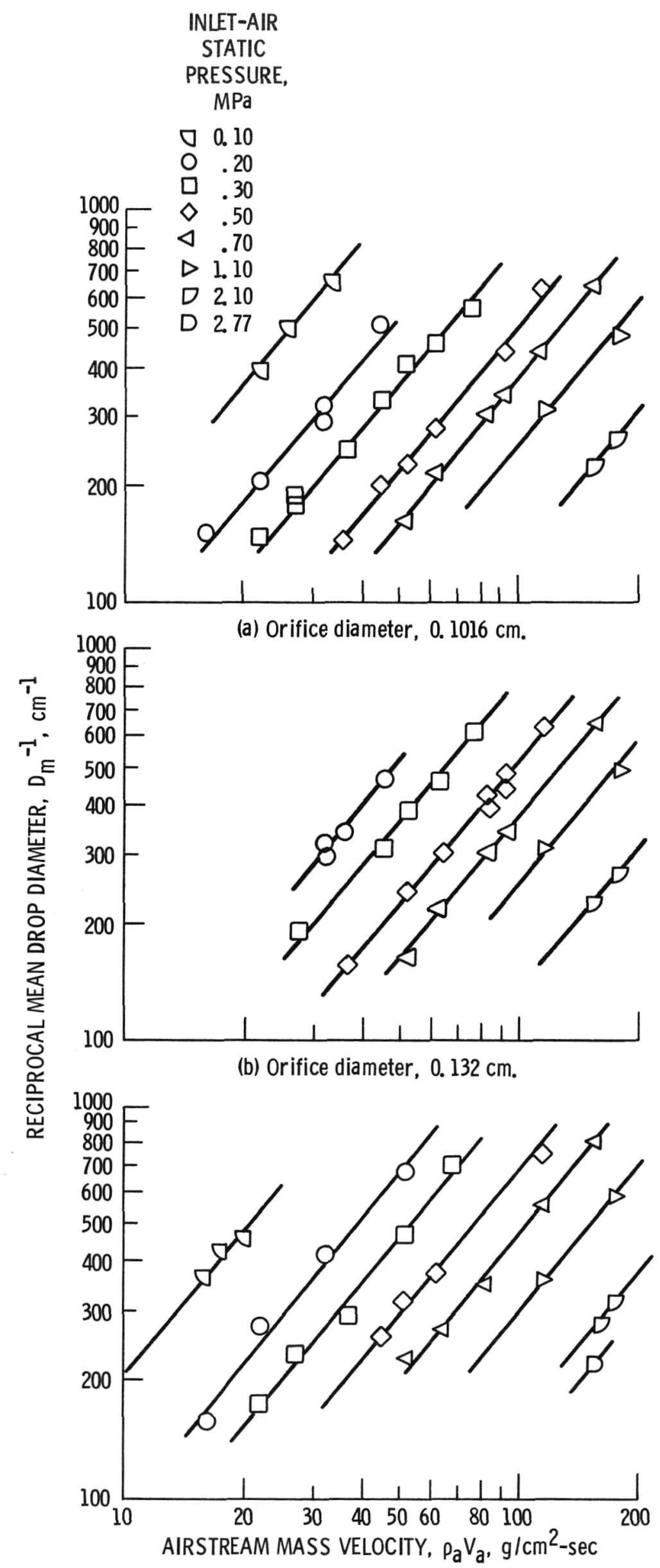

(c) Orifice diameter, $0.033 \mathrm{~cm}$.

Figure 7. - Variation of reciprocal mean drop diameter, $D_{m}{ }^{-1}$, with airstream mass velocity, $P_{a} V_{a}$. 


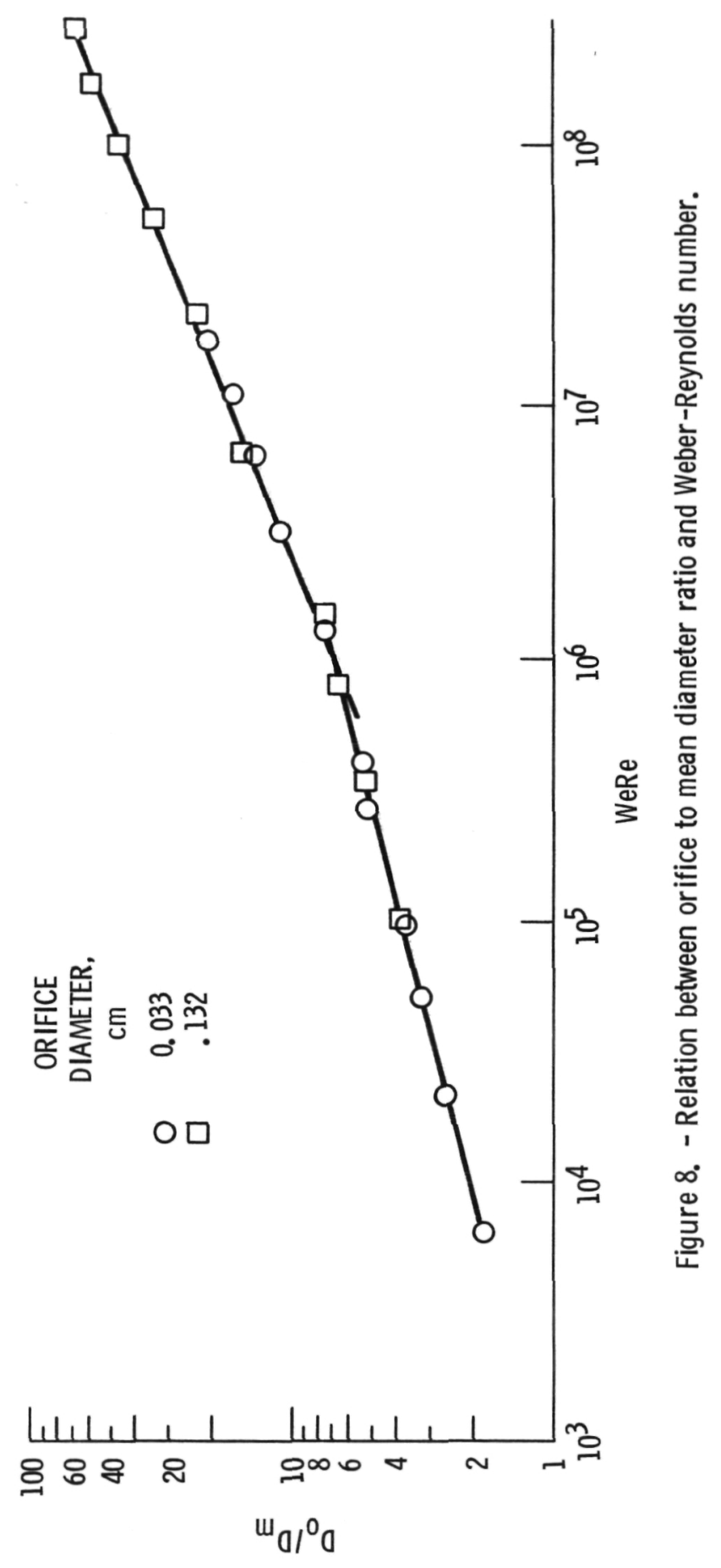



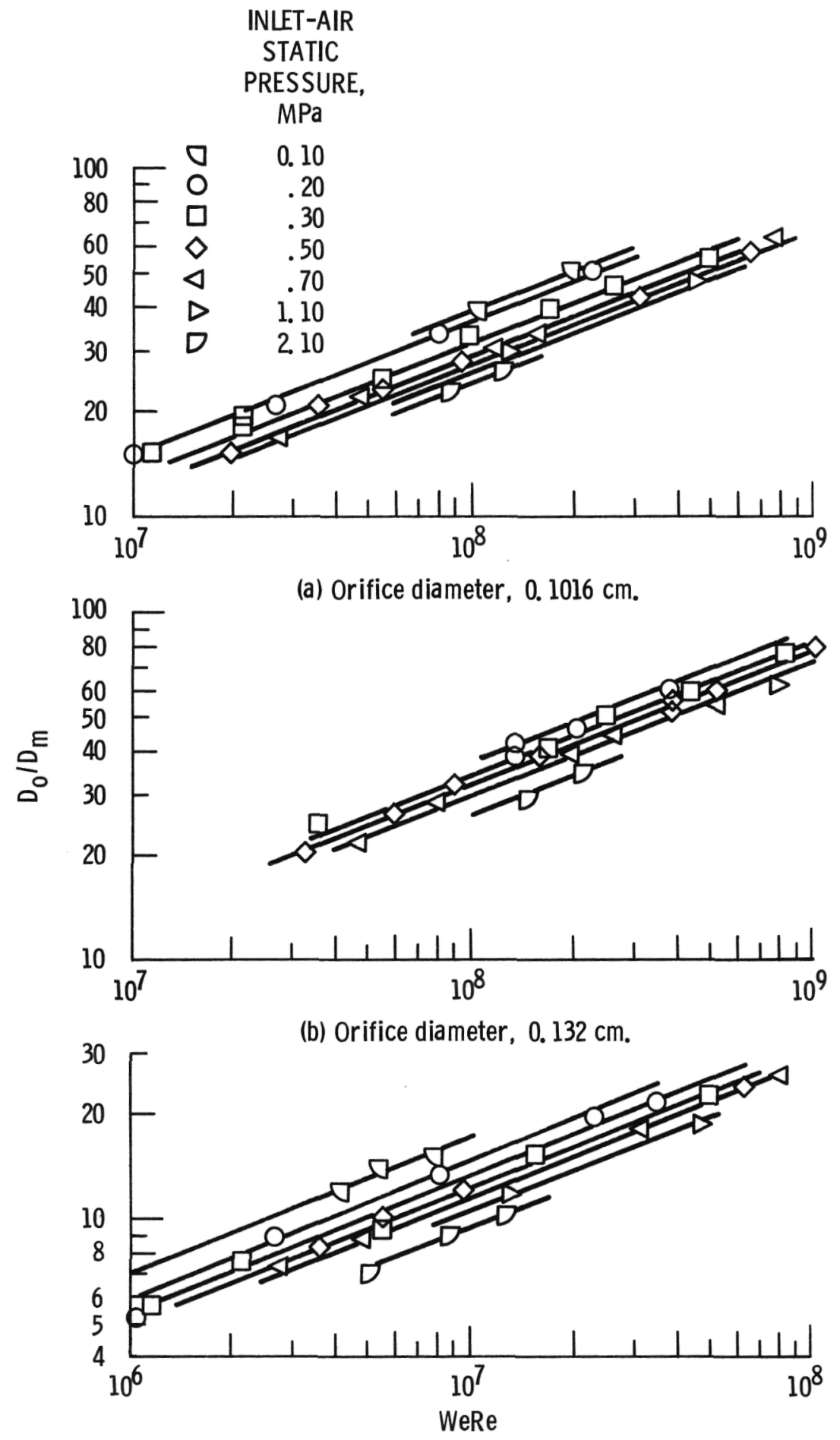

(c) Orifice diameter, $0.033 \mathrm{~cm}$.

Figure 9. - Variation of mean drop diameter, $D_{m}$, with product of Weber and Reynolds number. 

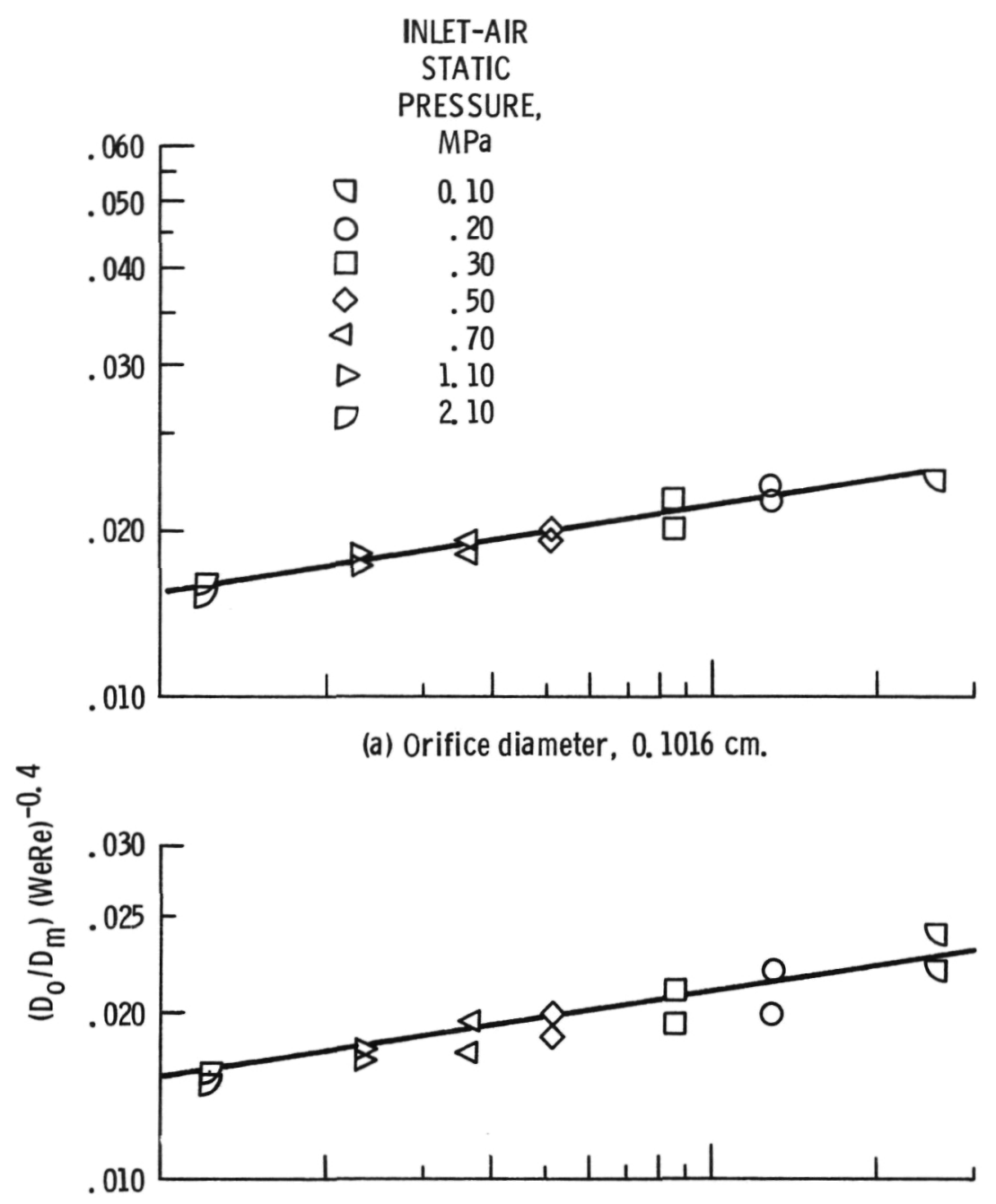

(b) Orifice diameter, $0.033 \mathrm{~cm}$.

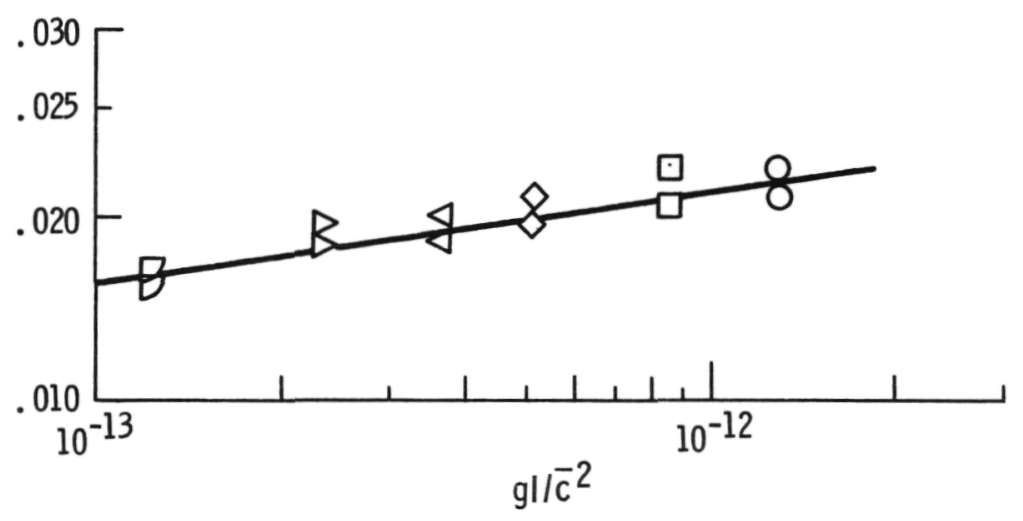

(c) Orifice diameter, $0.132 \mathrm{~cm}$.

Figure 10. - Correlation of mean drop diameter, $D_{m}$, with dimensionless group gl/ $\bar{c}^{2}$. 


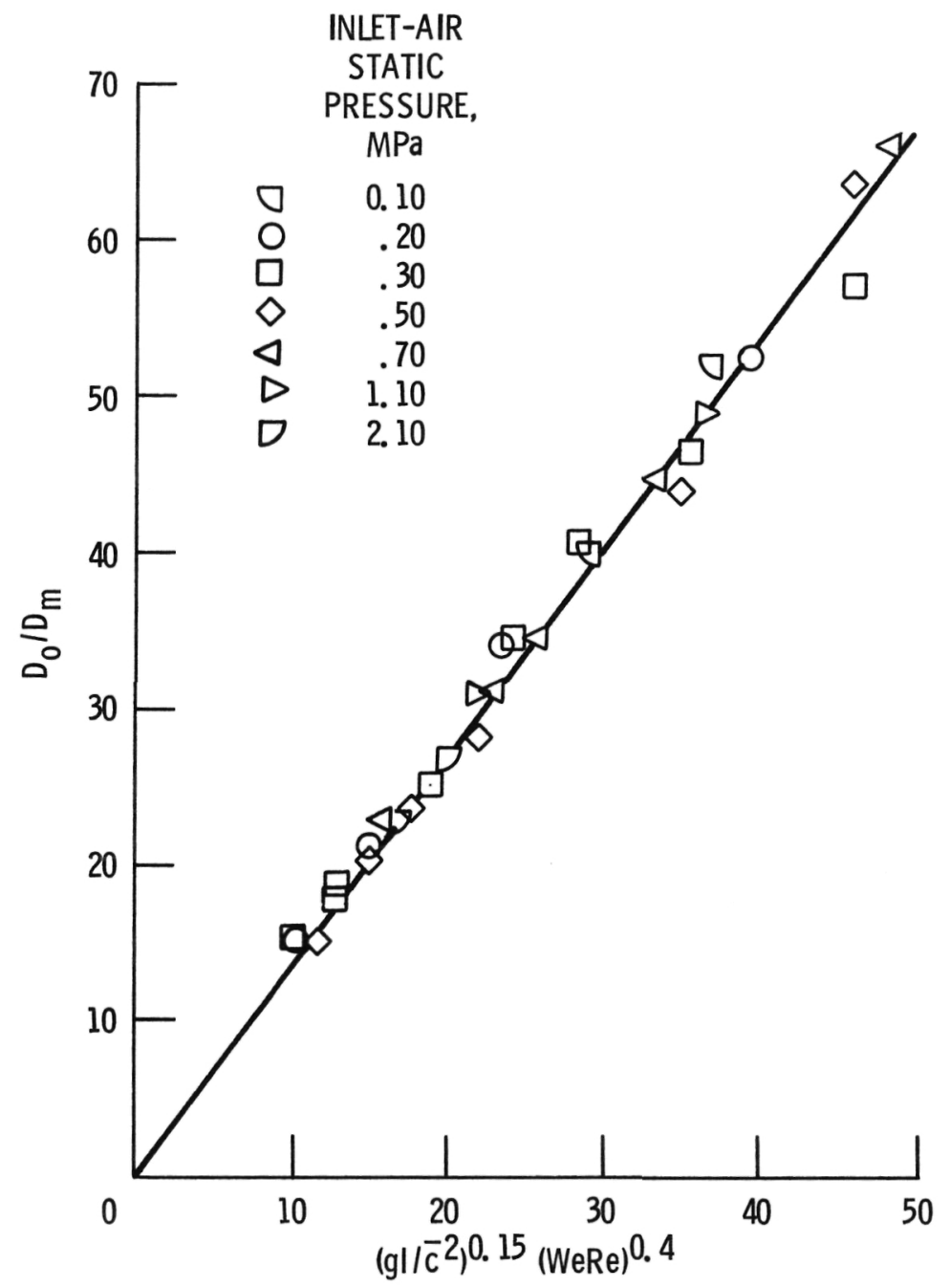

(a) Orifice diameter, $0.1016 \mathrm{~cm}$.

Figure 11. - Correlation of mean drop diameter, $D_{m}$, with dimensionless groups $\mathrm{gl} / \overline{\mathrm{c}}^{2}$ and WeRe. 


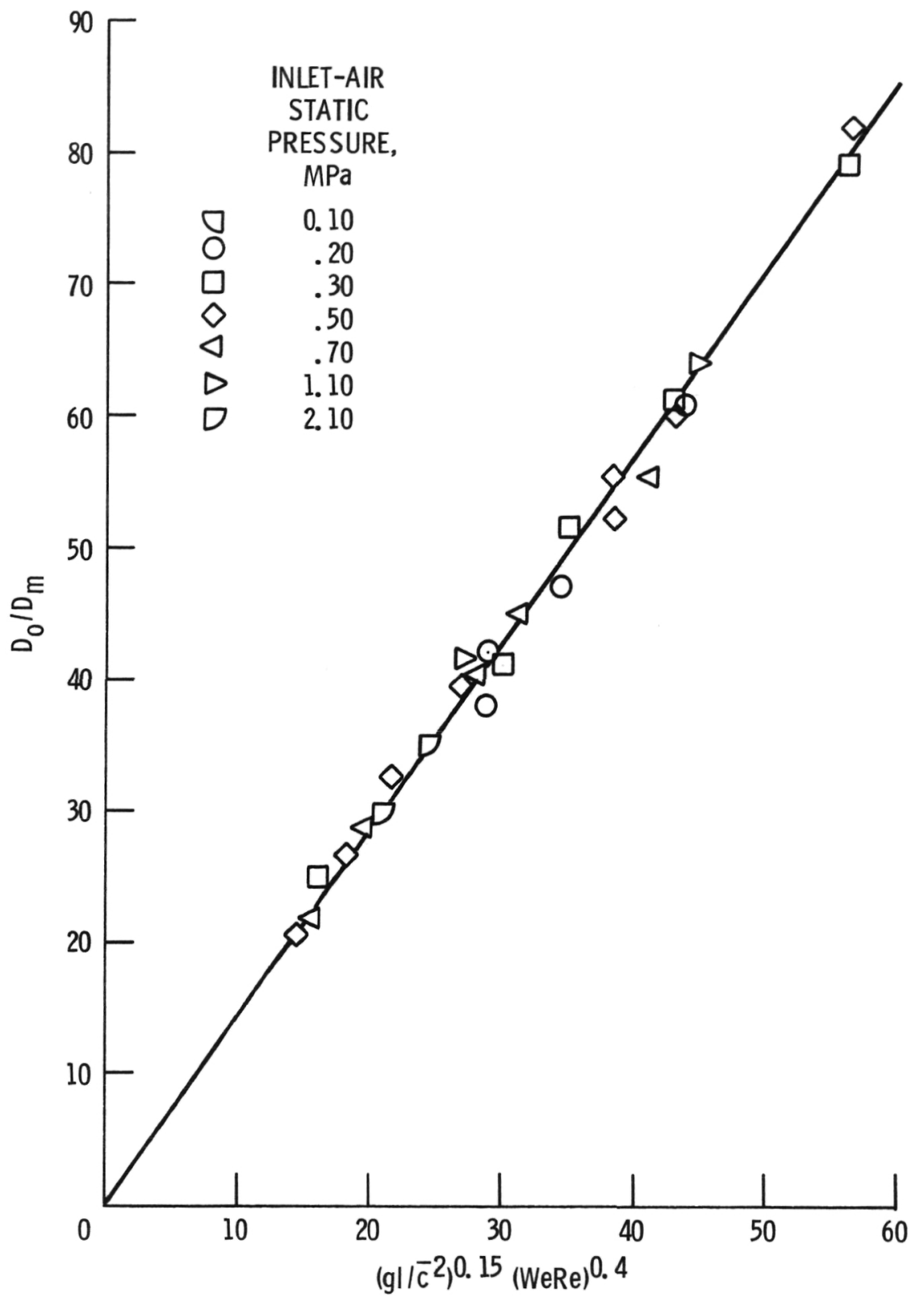

(b) Orifice diameter, $0.132 \mathrm{~cm}$.

Figure 11. - Continued. 


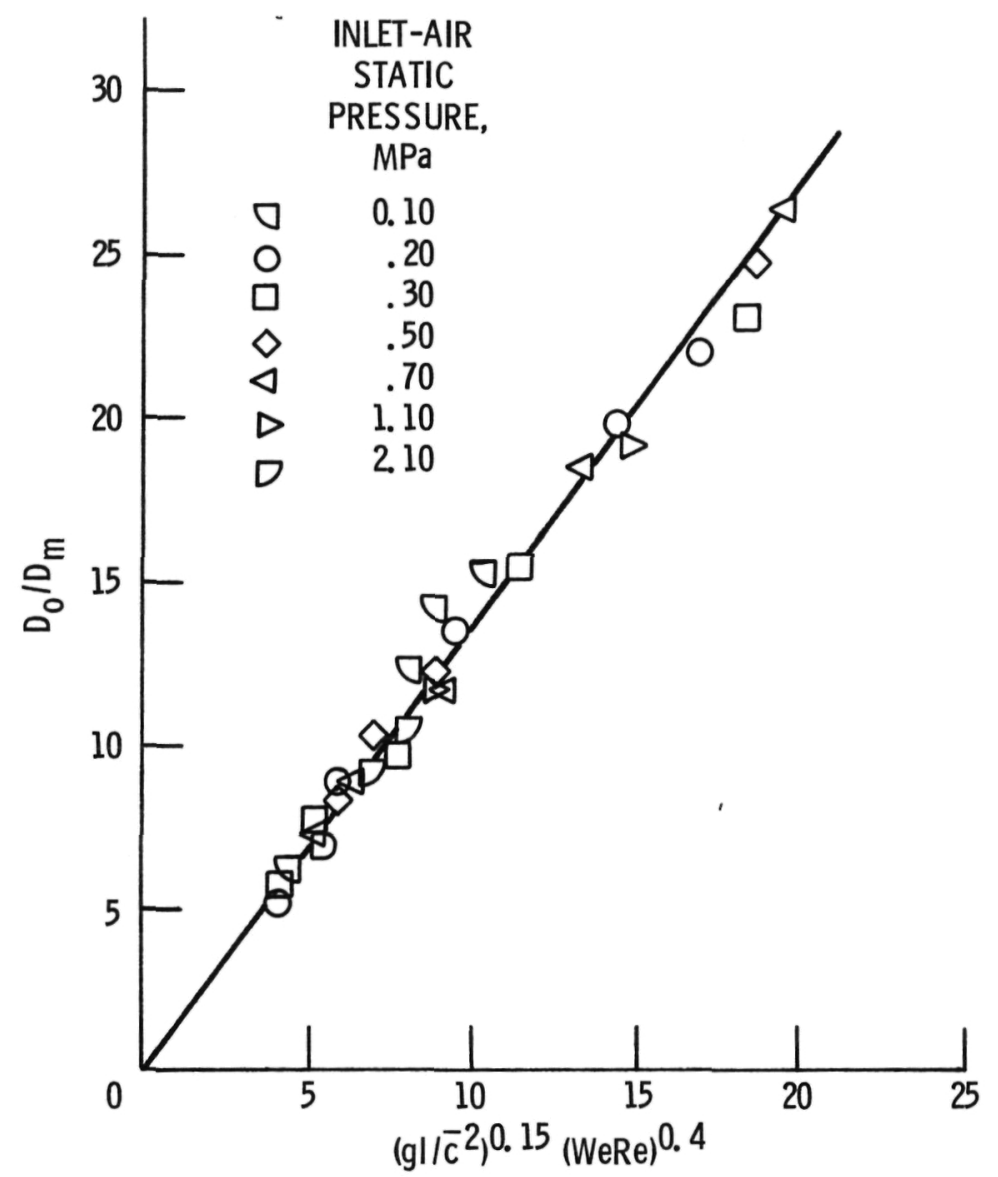

(c) Orifice diameter, $0.033 \mathrm{~cm}$.

Figure 11. - Concluded. 


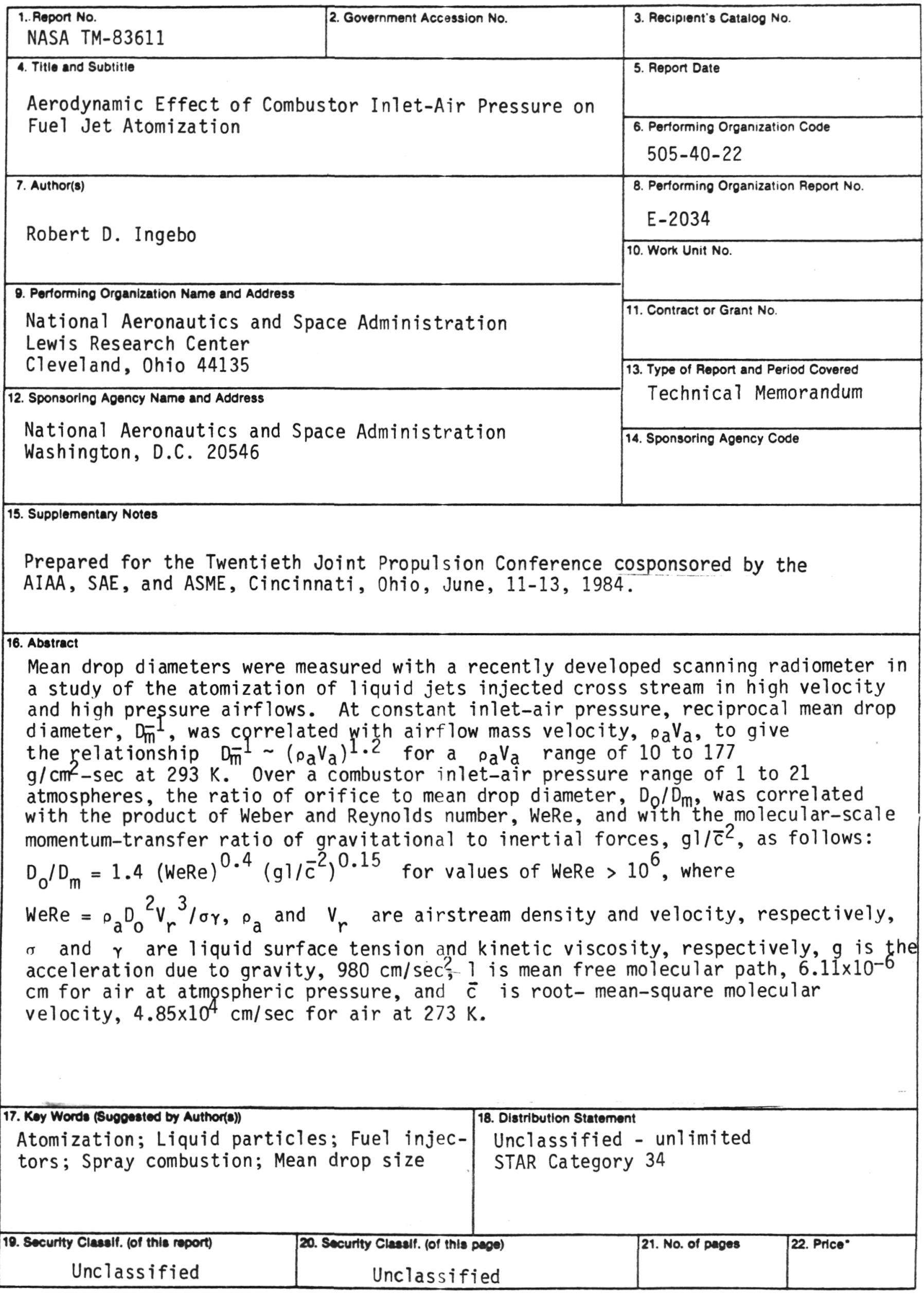


National Aeronautics and Space Administration

Washington, D.C.

20546

Official Business

Penalty for Private Use, $\mathbf{\$ 3 0 0}$
SPECIAL FOURTH CLASS MAIL BOOK

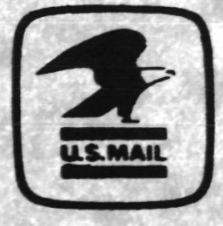

Postage and Fees Paid National Aeronautics and Space Administration NASA-451 